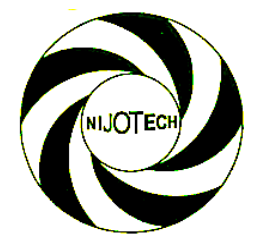

Nigerian Journal of Technology (NIJOTECH)

Vol. 36, No. 2, April 2017, pp. $611-620$

Copyright@ Faculty of Engineering, University of Nigeria, Nsukka,

Print ISSN: 0331-8443, Electronic ISSN: 2467-8821 www.nijotech.com

http://dx.doi.org/10.4314/njt.v36i2.37

\title{
HARMONICS MITIGATION ON INDUSTRIAL LOADS USING SERIES AND PARALLEL RESONANT FILTERS
}

\author{
I. A. Adejumobi ${ }^{*}$, O. I. Adebisi ${ }^{2}$ and J. E. Amatu ${ }^{3}$ \\ 1,2,3 Dept of Electrical and Electronics Engr., Federal Univ. of Agriculture, AbeokUta. Ogun State, NiGERIA \\ E-mail addresses: ${ }^{1}$ engradejumobi@yahoo.com, ${ }^{2}$ adebisi.oluwaseun@yahoo.com, ${ }^{3}$ amatujenifer.aj@gmail.com
}

\begin{abstract}
Most industrial loads are inductive in nature and therefore absorb Volts Ampere Reactance (VARs) leading to lagging power factor. Some inductive loads also produce current and voltage signals with frequencies in integer multiples of the 50 or $60 \mathrm{~Hz}$ fundamental frequencies called harmonics. Harmonics in power system causes several problems ranging from overheating, premature equipment failure, false tripping of protective relays resulting in unnecessary down time in industrial production. This work compared the use of series and parallel resonant harmonic filters in suppressing harmonics using Simulink model of the power system of NICHEMTEX, a Textile industry in Nigeria as a case study. Mathematical analysis representing current harmonics distributions on industrials loads with and without capacitor banks were presented. From the analysis, series resonant filter mitigated the total harmonic distortion from $30.080 \%$ to 3.460\%. The installation of capacitor bank along with the series resonant filter in the industrial facility, further reduced the total harmonic distortion to $0.001 \%$ and power factor compensated from 0.860 to 0.894 . However, the use of parallel resonant filter mitigated the harmonic distortion to $8.107 \%$ and a reduction in the power factor from 0.860 to 0.840 . With the parallel resonant filter connection with the capacitor bank, harmonic distortion was mitigated to $0.140 \%$, and the power factor reduced to 0.553 , the value which is very low. Hence, it is observed that for this sample case, the use of series resonant filter mitigated the harmonics distortion and maintained power factors within the acceptable IEEE standard values.
\end{abstract}

Keywords: Industrial inductive loads, Harmonics, Harmonic distortions, Power factor correction, Series resonant filter, Parallel resonant filter

Nomenclature

$\mathrm{f}_{\mathrm{o}} \quad$ Resonance frequency

$\mathrm{X}_{\mathrm{L}}$ Inductive reactance

$\mathrm{X}_{\mathrm{C}} \quad$ Capacitive reactance

$Q_{1}$ Load reactive power before power factor improvement

$Q_{2}$ Load reactive power after power factor improvement

$Q^{*} \quad$ Net load reactive power after power factor improvement

$Q_{p h}$ Per phase net load reactive power after power factor improvement

$p f_{1} \quad$ Load power factor before improvement

$p f_{2}$ Load desired power factor after improvement

$\mathrm{X}_{\mathrm{F}} \quad$ Filter capacitive reactance

$h \quad$ Harmonics

$n$ Harmonic order,

f System frequency

L Inductance

C Capacitance
$\mathrm{C}_{1}$ Voltage/current magnitude of the fundamental component

$\mathrm{C}_{\mathrm{k}}$ Voltage/current magnitude of the harmonic components $(\mathrm{k}=2,3,4 \ldots)$

$I_{T H D}$ Total harmonic distortion for current

$I_{k} \quad$ Harmonic distortion for the current at different harmonic orders.

$Q_{L} \quad$ Per phase load inductive reactive power

$Q_{C} \quad$ Per phase load inductive reactive power.

\section{INTRODUCTION}

Power quality problem is a germane issue in power system and is of great concern to electrical power and control engineers. Basically, power systems are designed to operate at specified fundamental frequency of 50 or $60 \mathrm{~Hz}$. However, certain types of loads most especially inductive loads which are characteristically non-linear, produce current and voltage waveforms with frequencies that are integral multiples of the 50 or $60 \mathrm{~Hz}$ fundamental frequency. These higher frequencies are electrical pollution known as power system harmonics.

* Corresponding author, tel: + 234- $703-321-5455$ 
Presence of harmonics in power system results in distortion of supply system base waveform and this has deleterious effects on the performance of many industrial applications high technology devices related to communication, advanced control, automation, precise manufacturing technique and on-line services [1]. Due to the increase in the usage of non-linear loads in industrial applications, most especially Variable Frequency Drives (VFDs), problem of harmonics in power system has attracted significantly the attention of researchers globally. While VFDs play significant role in enhancing system efficiency and provide great energy saving, their vulnerability to harmonics generation poses great threat to their widespread applications [2, 3].

Industrial, commercial and domestic consumers require high quality electricity supply for healthy operation of their electrical devices and equipment but with a distorted electricity supply, the chances of improved performance of their electrical systems is drastically reduced. In order to minimise the resultant adverse effects of harmonics arising from the incessant use of non-linear loads on electrical plant and equipment, it is very imperative to device means of mitigating harmonics. The mitigation of the power system harmonics is of great importance in industrial electrical systems in order to increase system reliability, enhance operation economics, avoid unwanted equipment failure and process downtimes [4]. Harmonics studies in power system include among others analyses of voltage and current levels in the system and to check if the values comply with the IEEE standard limit. Whenever the limit is violated, a suitable mitigation technique should be applied.

Various techniques of harmonics mitigation have been reported in literature with some findings implemented [5-10]. The use of active filters over passive filters for power conditioning was proposed in Akagi [5], Shahbaz [6] and Dutta et al. [7]. While Akagi [5] and Shahbaz [6] opined that active filters offer multiple functions including harmonic filtering, damping, isolation and termination, reactive power control for power factor correction and voltage regulation, load balancing and voltage flicker reduction, Dutta et al. [7] also claimed that active filters provide fast control response and more flexibility in defining the required control tasks for particular applications over passive filters. However, these advantages come at the expense of cost and operating loss Akagi [5]. Lee et al. [8] proposed hybrid active filter with variable conductance for use as harmonic resonance suppressor in industrial power systems. They argued that apart from avoiding harmonic resonance and maintaining harmonic distortion within an acceptable level in case of load changes and variations of line impedance of the power system, a reasonable trade-off between filtering performances and cost can be achieved using hybrid active filters. Schwanz et al. [9] presented a review of solutions for harmonic mitigation where he described the pros and cons of active, passive and hybrid solutions. He observed that depending on situations, the use of more than one solution is recommended and that in most cases hybrid solution is the best option, since it combines technologies with varying characteristics. de Campos et al. [10] proposed mitigation of harmonic distortion using passive filters. He noted that the main advantage of passive filter is its cost; however, this filter is prone to the problem of resonances with electric system elements and hence, can result in general undesirable system performances.

This research work therefore analytically compares the use of series and parallel resonant filters, two of the basic configurations of active filters, in mitigating the effects of harmonics distortion resulting from the use bank of capacitors and non-linear loads in industries considering power supply network of NICHEMTEXT Industry in Nigeria as a case study. To quantify the distortion, the term total harmonics distortion (THD) is used. The THD value is the effective value of all the harmonics current added together and compared with the value of the fundamental current [11].

\section{HARMONICS IN POWER SYSTEM: SOURCES AND EFFECTS}

One of the main sources of harmonics in power system is non-linear loads. The proliferation of non-linear loads and sources, such as power electronic based equipment, has led to a serious problem of power quality for both utility and customers as these non-linear elements are the main contributors of harmonic pollution in power system. A non-linear load is a device whose current is not proportional to the applied voltage [12]. Active nonlinear loads produce voltage harmonics and current harmonics, because the resistances of such load devices are usually not constant since it changes during each sine wave. Typical examples of harmonics sources include fluorescent lighting, computer switch mode power supplies, static var compensators, variable frequency motor drives, dc-dc converters, inverters, chillers etc. [13].

When considering utility distribution feeders linking to industrial plant power systems, there is tendency for the harmonic currents flowing from the harmonic producing loads to be transported to the power system source, the effect of which is inimical to other loads connecting to the source. Harmonics generated in one part of the system results to increase in the resonance effects in another part. Some resonance can be dangerous if the magnification is large because of high circuit Q-factor or low damping. As a result of increased current flowing in 
the system, the effect of current distortion on power distribution systems can be serious. Harmonic current occurring in a facility's electrical system can cause data distortion, transformer and motor insulation failure, overheating of neutral buses, tripping of circuit breakers, and solid-state component breakdown. Harmonic currents increase heat losses in transformers and wiring. Since transformer impedance is frequency dependent, the impedance at harmonic frequencies is much higher than at fundamental frequency. So each ampere of harmonic current causes higher heating effect compared to the ampere of fundamental current [14].

Capacitors are used by both electricity utilities and customers to improve their power factor. Resonance due to capacitor banks can magnify the harmonic problems. There is an intermediate range of frequencies where the capacitive and inductive effects can combine to give very high impedance. A small harmonic current within this frequency range can give a very high and undesirable harmonic voltage, the condition which is called resonance [15].

\subsection{Minimization of Harmonics in Power System}

In order to ensure continuous acceptable power quality on small and medium power distribution systems, it is necessary to minimize harmonics present on supply systems. Harmonic minimization can be performed using filters in various forms.

Resonant filters could be passive or active depending on its desired applications. Series LC circuits give minimum impedance at resonance, series resonant LC band-pass filter passes signal at resonance and blocks signals of any other frequencies from getting to the load. LC low pass filter allows low frequencies to pass through but attenuated to great extent all higher frequencies. The maximum frequency which it allows to pass through is the cut-off frequency. LC band stop filter is a resonant circuit which is tuned to pass certain band or range of frequencies while rejecting all frequencies below and above this range called pass band [16].

Passive LC filters comprising inductors, capacitors and occasionally resistors have been utilized for harmonic mitigation for many years. Their operation relies on the phenomenon of resonance which occurs due to variations in frequency in inductors and capacitors. The most common type of shunt passive filters is the singletuned notch filter. This is the most economical type and is frequently sufficient for the application. The notch filter is series-tuned to present low impedance to a particular harmonic current and is connected in shunt with the power system. Therefore, harmonic currents are diverted from their normal flow path on the line through the filter. Notch filters provide power factor correction in addition to harmonic suppression.

\subsubsection{Power Factor Correction Using Capacitor Banks versus Harmonics Reduction Using Resonant Filters.}

Industrial loads operate on lagging power factor, being inductive in nature. To improve the power factor, a bank of capacitors is usually connected across loads. Authentications of the level of power factor improvement are altered with the presence of resonant filters, when harmonics reduction may be achieved using filters. This condition poses a problem such that the exact desired system power factor may be difficult to achieve.

\section{THEORETICAL ANALYSIS OF ELECTRICAL RESONANCE}

In electrical networks, series resonance occurs when an inductor and a capacitor are connected in series and they resonate together at a certain resonance frequency $f_{o}$ such that $\mathrm{X}_{\mathrm{L}}$ and $\mathrm{X}_{\mathrm{C}}$ are equal. A typical series resonant circuit is shown in Figure 1. The negligible impedance of the series resonant circuit can be exploited to absorb desired harmonic currents. This is indeed the principle in designing a notch filter [17].

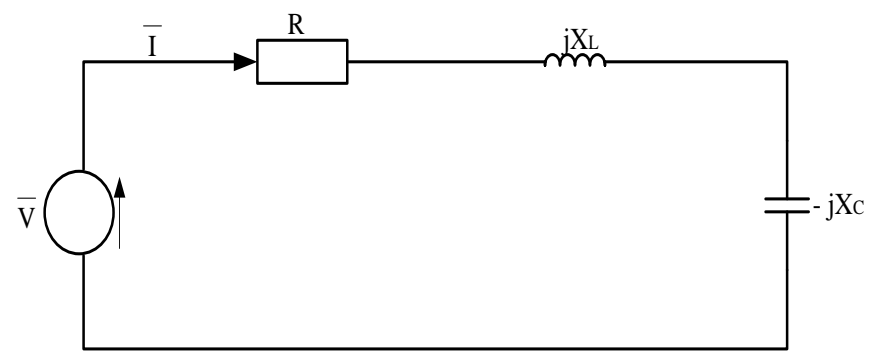

Figure 1: A series resonant circuit

\subsection{Resonance Filter}

An electrical filter is a network that can be designed to modify, reshape or reject all unwanted frequencies of an electrical signal and accept or pass only those signals wanted by the network designer. One major disadvantage of a network comprising frequency dependent components such as capacitors and inductors is the ability of network to resonate at harmonic frequency which results in undesirable condition under which the overall system can effectively operate. Figure 2 is a typical circuit of an industrial inductive load whose power factor is to be improved using a bank of capacitors. Figures 3 and 4 respectively show the connections when series and parallel resonant filters are considered for suppressing harmonics on the entire system.

By considering an industrial load $\mathrm{S}$ in VA, operating on lagging power factor $\cos \theta$, the active power $\mathrm{P}$ in Watts and reactive power $Q$ in Var are related to $S$ by equations (1) to (4): 


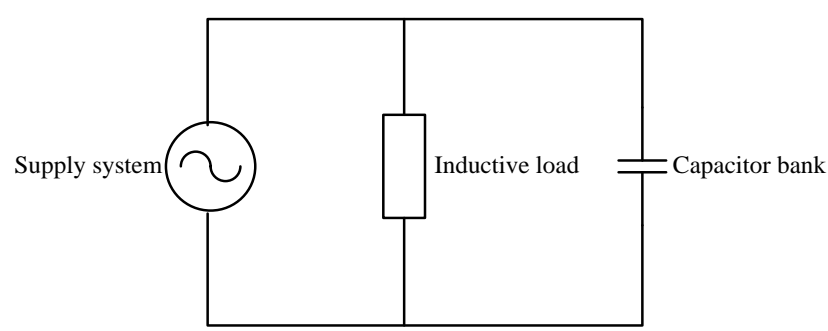

Figure 2: Inductive load with capacitor bank for power factor improvement

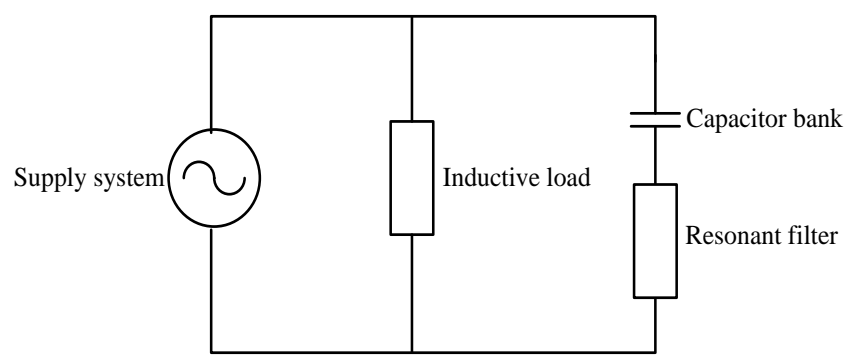

Figure 3: Series resonant filter

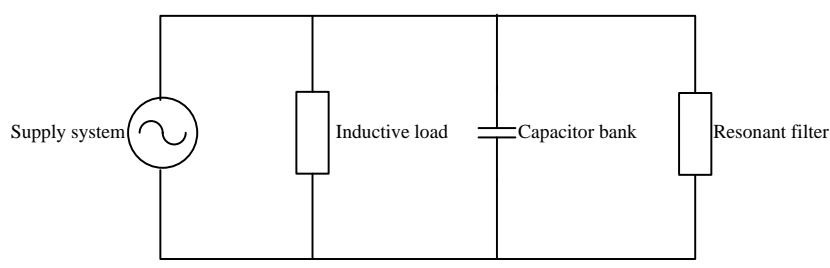

Figure 4: Parallel resonant filter

$$
\begin{aligned}
& S=P_{\text {Load }}+j Q_{\text {Load }} \\
& S=\sqrt{P^{2}+Q^{2}} \\
& P=S \cos \theta \\
& Q=S \sin \theta
\end{aligned}
$$

The modelling equations for the series resonant harmonic filter shown in Figure 3 are given by equations (5) to (13):

$$
\begin{aligned}
& Q_{1}=S \times \sin \left(\cos ^{-1}\left(p f_{1}\right)\right) \\
& Q_{2}=S \times \sin \left(\left(\cos ^{-1}\left(p f_{2}\right)\right)\right. \\
& Q^{*}=Q_{1}-Q_{2} \\
& Q_{p h}=\frac{Q^{*}}{3}
\end{aligned}
$$

From [17],

$$
\begin{aligned}
& \left\{\begin{array}{c}
X_{f}=\left(\frac{V}{1000}\right)^{2} \times \frac{1000}{Q} \\
X_{C}=X_{f} \times \frac{h^{2}}{h^{2}-1} \\
h=\left(1-\frac{6}{100}\right) \times n \\
X_{L}=\frac{X_{C}}{h^{2}}
\end{array}\right. \\
& C=\frac{1}{2 \pi f X_{C}} \\
& L=\frac{X_{L}}{2 \pi f}
\end{aligned}
$$

Where $Q_{1}, Q_{2}, Q^{*}$, and $Q_{p h}$ are in Var, $\mathrm{X}_{\mathrm{L}}, \mathrm{X}_{\mathrm{C}}$ and $\mathrm{X}_{\mathrm{F}}$ are in $\Omega$, $\mathrm{f}$ is in $\mathrm{Hz}, \mathrm{L}$ is in $\mathrm{H}$ and $\mathrm{C}$ is in $\mathrm{F}$.

THD is a measure of the effective value of the harmonic components of a distorted waveform, that is, it is the potential heating value of the harmonics relative to the fundamental. This index is calculated for either voltage or current by [17] and it is given by equation (12):

$$
\begin{gathered}
\left\{T H D=\frac{\sqrt{\sum_{k=2}^{\infty} C_{k}^{2}}}{C_{1}} \times 100 \%, \quad I_{T H D}=\sqrt{\sum_{\mathrm{k}=2}^{\infty} \mathrm{I}_{\mathrm{k}}^{2}}\right. \\
\text { With } \quad I_{k}=\frac{C_{k}^{2}}{C_{1}} \times 100 \%
\end{gathered}
$$

$\mathrm{C}_{1}$ and $\mathrm{C}_{\mathrm{k}}$ are usually obtained experimentally. However, for the purpose of this research work, they were obtained from MATLAB/Simulink simulations of the sample system.

Modelling of parallel resonant harmonic filter is done in similar manner as that of the series resonant harmonic filter but with slight modifications given by equations (14) to (18). All variables are as defined before.

$$
\begin{gathered}
Q_{p h}=Q^{*} \\
Q_{L}=Q_{p h} \\
X_{L}=\frac{V^{2}}{Q_{L}} \\
L=\frac{X_{L}}{2 \pi}
\end{gathered}
$$

From [17],

$$
Q_{L}=h Q_{C}
$$

Where $Q_{L}$ and $Q_{C}$ are in Var.

For power factor correction, we require equations (19) to (21):

$$
\begin{aligned}
& \left\{\begin{array}{l}
Q_{C}=Q_{p h}+Q_{L} \\
Q_{C}=Q_{p h}+Q_{L} \\
Q_{C}=\frac{Q_{p h}}{(1-h)}
\end{array}\right. \\
& Q_{C}=\frac{V^{2}}{X_{C}} \\
& C=\frac{1}{2 \pi f X_{C}}
\end{aligned}
$$

\subsection{Standard Voltage and Harmonic Current Distortion Limits}

IEEE Std. 519-1992 is a standard developed for utility companies and their customers in order to limit harmonic content and provide users with better power quality. This standard is titled "IEEE Recommended Practices and Requirement for Harmonic Control in Electrical Power Systems". Tables 1 and 2 illustrate the recommended limits for THD and individual harmonic distortion for current and voltage at Point of Common Coupling (PCC). 
Table 1: Voltage distortion limit

\begin{tabular}{lcc}
\hline $\begin{array}{l}\text { Bus Voltage at } \\
\text { PCC }\end{array}$ & $\begin{array}{c}\text { Individual Voltage } \\
\text { Distortion }\end{array}$ & $\begin{array}{c}\text { Total Voltage } \\
\text { Distortion }\end{array}$ \\
\hline $\begin{array}{l}69 \mathrm{kV} \text { and } \\
\text { below }\end{array}$ & $3.0 \%$ & $5.0 \%$ \\
$69.001 \mathrm{kV}-161$ & $1.5 \%$ & $2.5 \%$ \\
$\mathrm{kV}$ & $1.0 \%$ & $1.5 \%$ \\
$\begin{array}{l}161.001 \mathrm{kV} \text { and } \\
\text { above }\end{array}$ & Source [18]
\end{tabular}

Table 2: Maximum Harmonic Current Distortion (\%) of $I_{I}$ Individual Odd Harmonic Order

\begin{tabular}{lcccccc}
\hline Isc/IL Ratio & $<11$ & $\begin{array}{c}11 \leq \mathrm{h} \\
<17\end{array}$ & $\begin{array}{c}17 \leq \mathrm{h}< \\
23\end{array}$ & $\begin{array}{c}23 \leq \mathrm{h}< \\
35\end{array}$ & $\begin{array}{c}35 \leq \\
\mathrm{h}\end{array}$ & $\begin{array}{c}\text { TDD- } \\
\text { I } \\
\text { limit }\end{array}$ \\
\hline$<20$ & 4.0 & 2.0 & 1.5 & 0.6 & 0.3 & $5 \%$ \\
$20<50$ & 7.0 & 3.5 & 2.5 & 1.0 & 0.5 & $8 \%$ \\
$50<100$ & 10.0 & 4.5 & 4.0 & 1.5 & 0.7 & $12 \%$ \\
$100<1000$ & 12.0 & 5.5 & 5.0 & 2.0 & 1.0 & $15 \%$ \\
1000 up & 15.0 & 7.0 & 6.0 & 2.5 & 1.4 & $20 \%$ \\
\hline \multicolumn{7}{c}{ Source [18] }
\end{tabular}

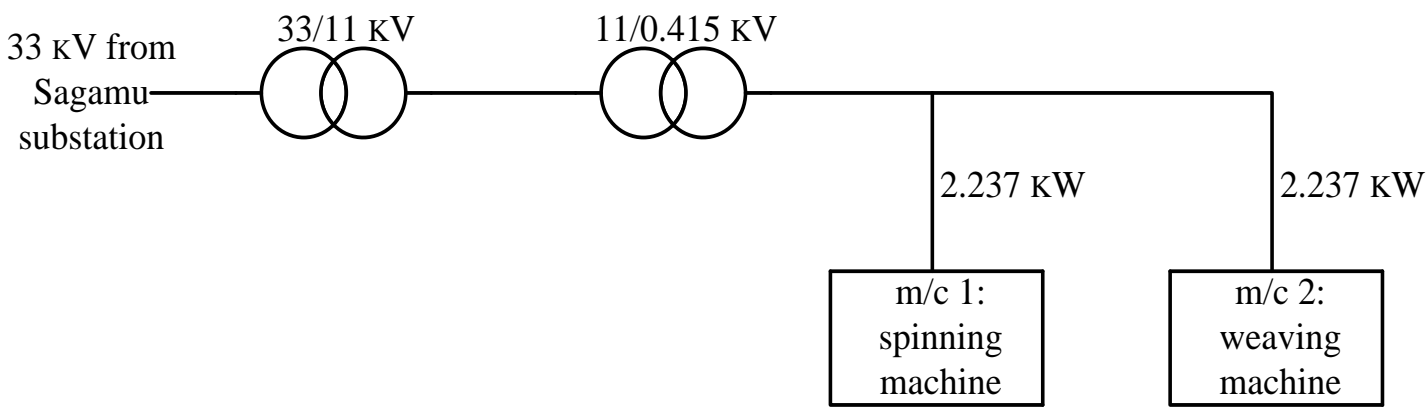

The NICHEMTEXT supply system

\subsection{System Modelling Using MATLAB/SIMULINK Software} For easy analysis and understanding, the sample system under consideration was built in MATLAB/Simulink environment. The model included sample system, capacitor banks, series and parallel resonant filters.

\subsubsection{SIMULINK Model Using NICHEMTEXT in Nigeria as a Case Study}

NICHEMTEXT is a textile industry in Nigeria. It is responsible for processing and distribution of textile products. The industry is fed from $33 \mathrm{kV}$ feeders. The 33 $\mathrm{kV}$ is step down to $11 / 0.415 \mathrm{kV}$ through a $7.5 \mathrm{MVA}$ power transformer which supplies weaving and spinning machines of the industry as shown in Figure 5. The two industrial machines are connected in parallel with individual capacitor bank. The weaving and spinning machines are rated 3h.p. each. The capacitor bank rating for spinning machine is $12.5 \mathrm{e} 3 \times 60 \mathrm{kVar}$ and for weaving is $12.5 \mathrm{e} 3 \times 42 \mathrm{kVar}$. The Simulink series and parallel resonant filter models of NICHEMTEXT major industrial loads are shown in Figures 6 and 7 respectively.

Figure 5:

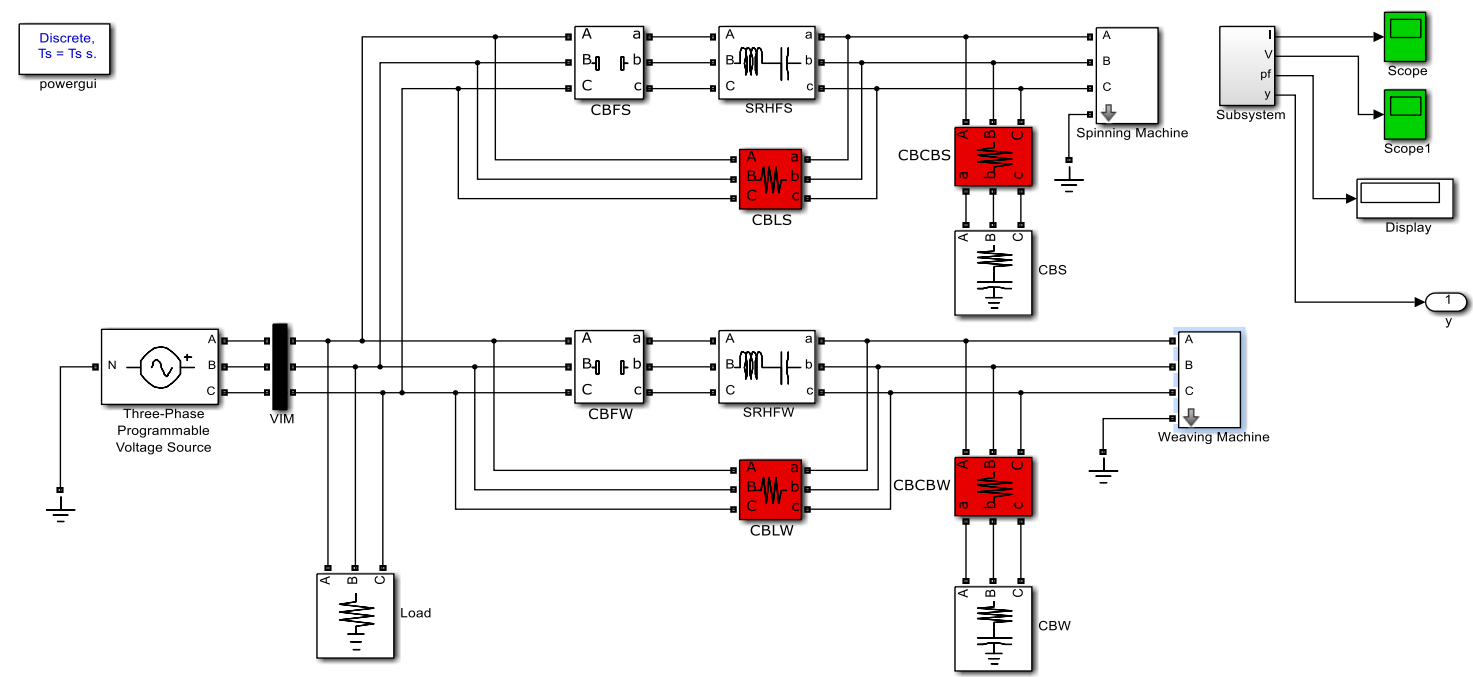

Figure 6: Simulink series resonant filter model of NICHEMTEXT major industrial loads 


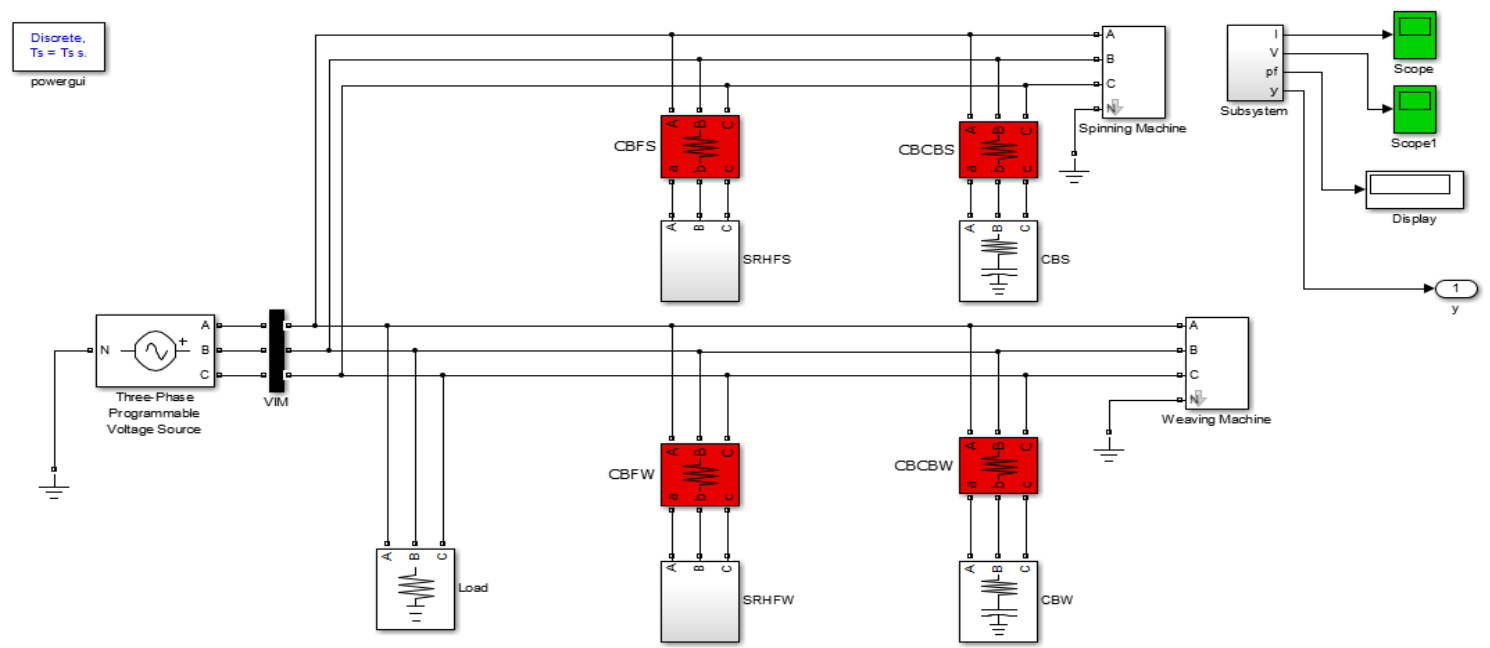

Figure 7: Simulink of parallel resonant filter model of NICHEMTEXT major industrial loads

\section{RESULTS AND DISCUSSION}

4.1 Simulation of Series Resonant Filter Model of NICHEMTEXT Major Industrial Loads without Series Resonance Harmonic Filter and Capacitor Bank

The circuit breaker in Figure 6 was switched on and the model was simulated without series resonant harmonic filter and capacitor bank. The results are shown in Figures 8, 9 and 10 respectively.

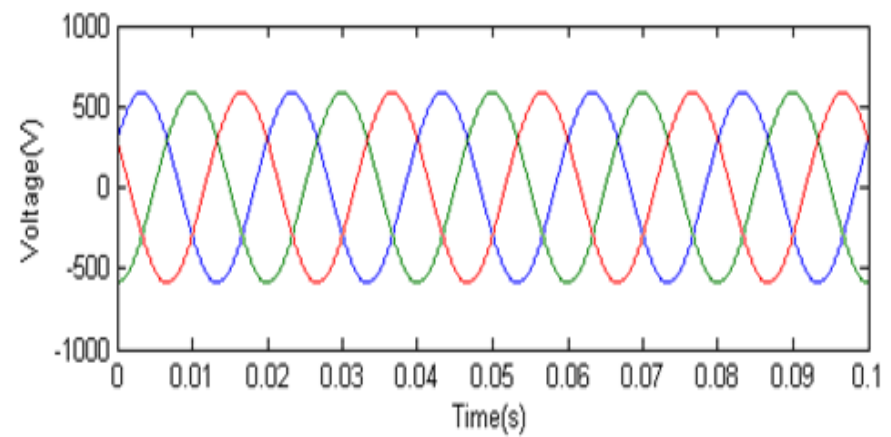

(a)

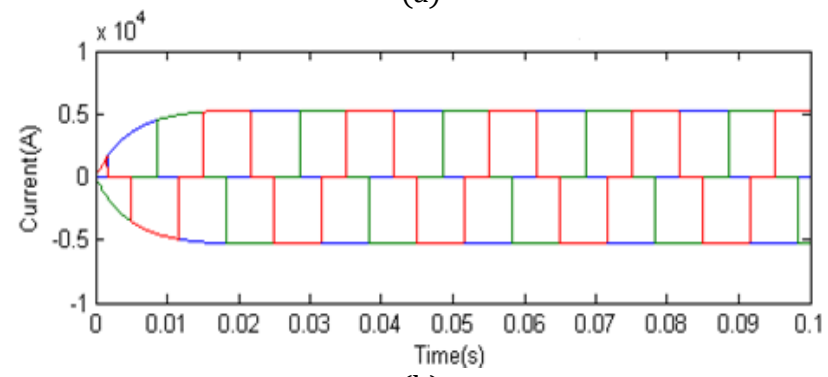

(b)

Figure 8: (a) Voltage waveform of series resonant filter model of NICHEMTEXT major industrial loads without series resonant harmonic filter and without capacitor bank (b) Current waveform of series resonant filter model of NICHEMTEXT major industrial loads without series resonant harmonic filter and without capacitor bank

The result shown in Figure 8a revealed that the voltage waveform of electricity supply system of NICHEMTEXT major industrial loads was undistorted when the Simulink series resonant filter model of the system was simulated without series resonant harmonic filter and capacitor bank. However, Figure 8b showed that the current waveform of the system was distorted, signifying the presence of harmonics.

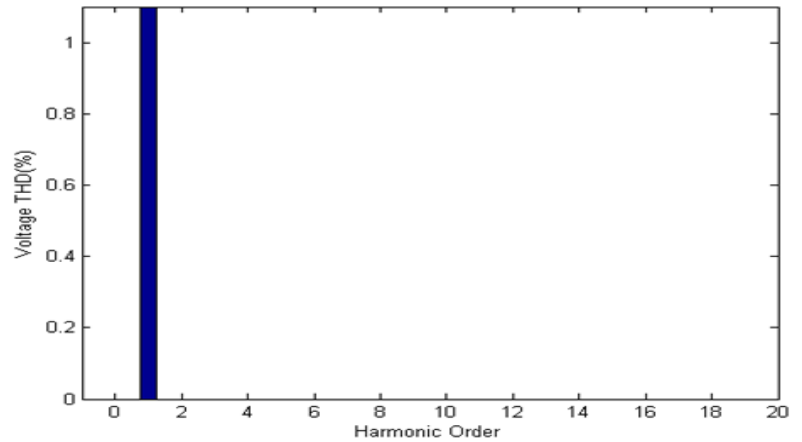

Figure 9: Voltage harmonic distortion of series resonant filter model of NICHEMTEXT major industrial loads without series resonant harmonic filter and without capacitor bank

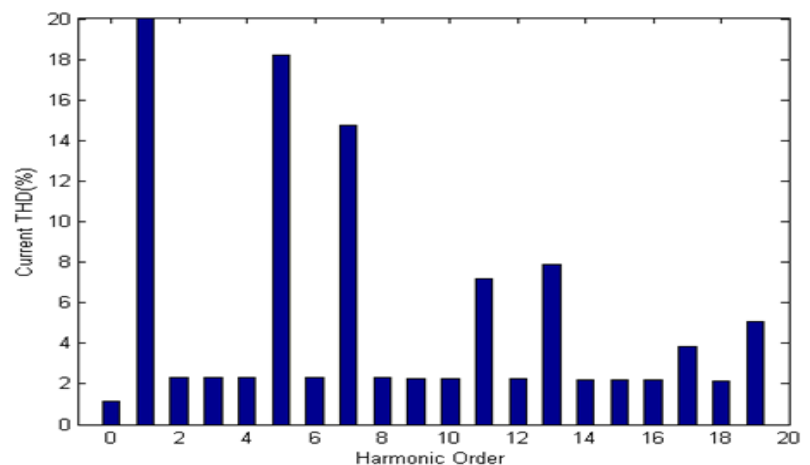

Figure 10: Current harmonic distortion of series resonant filter model of NICHEMTEXT major industrial loads without series resonant harmonic filter and without capacitor bank at various harmonic orders.

Figure 9 indicated the harmonic content showing in the system voltage at fundamental frequency has no negative impact on the system as the harmonic was of order 1 . Furthermore, the highest current harmonic distortion recorded during the simulation was $5^{\text {th }}$ order harmonic as presented in Figure 10 with a value of approximately $18.500 \%$ of the individual harmonic distortion, followed 
by $7^{\text {th }}, 11^{\text {th }}, 13^{\text {th }}$ order etc. The distortions of the different orders were presented as a percentage of the nominal value of the line current. The results of the simulation showed that, using equation 15, THD of current was $30.080 \%$ and the power factor reduced from 0.860 to 0.858.

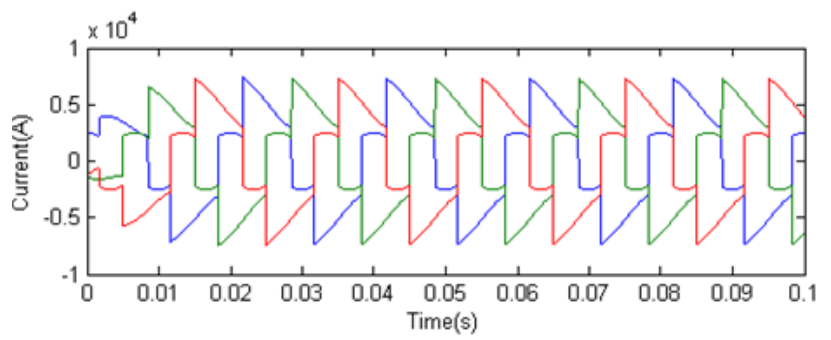

Figure 11: Current waveform of series resonant filter model of NICHEMTEXT major industrial loads without series resonant harmonic filter but with capacitor bank

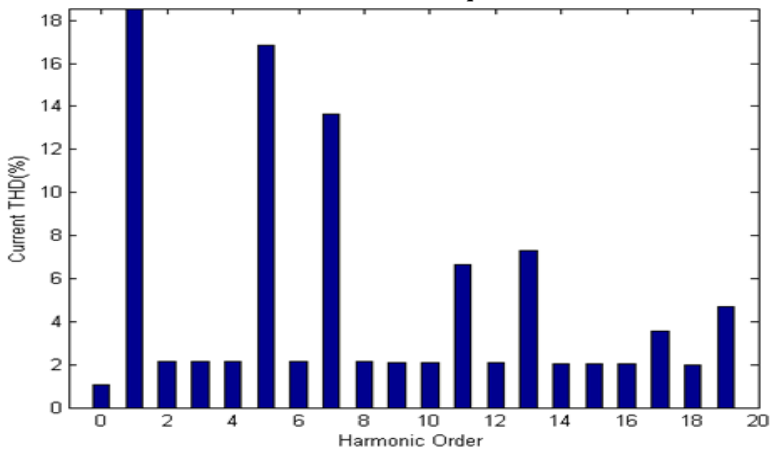

Figure 12: Current harmonic distortion of series resonant filter model of NICHEMTEXT major industrial loads without series resonant harmonic filter but with capacitor bank at various harmonic orders

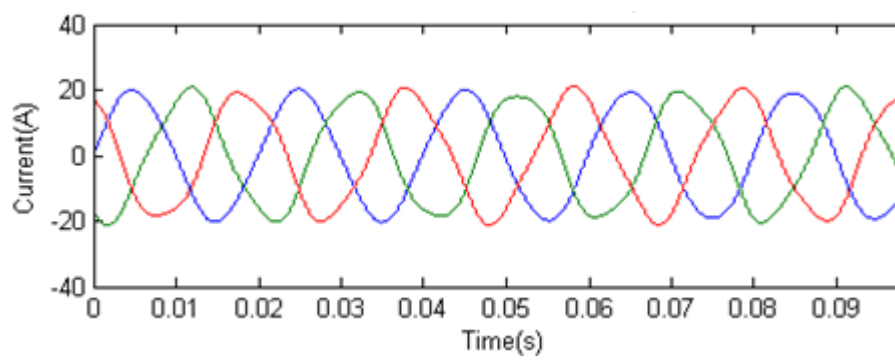

Figure 13: Current waveform of series resonant filter model of NICHEMTEXT major industrial loads with series resonant harmonic filter but without capacitor bank

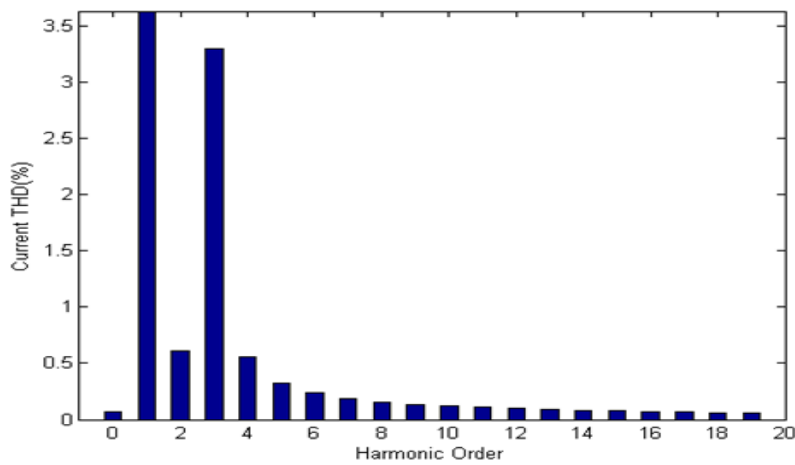

Figure 14: Current harmonic distortion of series resonant filter model of NICHEMTEXT major industrial loads with series resonant harmonic filter but without capacitor bank at various harmonic orders

\subsubsection{Simulation of Series Resonant Filter Model of} NICHEMTEXT Major Industrial Loads without Series Resonance Harmonic Filter but with Capacitor Bank

The circuit breaker in Figure 6 was switched on and the model was simulated without series resonant harmonic filter but with capacitor bank. The results are presented in Figures 11 and 12 respectively.

From Figure 11, it is obvious that though the current waveform was distorted but the level of distortion of the waveform is not high as that observed in the Figure $8 \mathrm{~b}$ due to the presence of the capacitor bank. However, from Figure 12 and using equation 15, THD of current was $27.790 \%$, giving a reduction of $2.290 \%$ compared to that obtained in Figure 10. Also, the power factor increased from 0.860 to 0.993 . The improvement in obtained results was due to the presence of the capacitor bank in the system.

\subsubsection{Simulation of Series Resonant Filter Model of NICHEMTEXT Major Industrial Loads with Series Resonance Harmonic Filter but without Capacitor Bank}

Similarly, the circuit breaker in Figure 6 was switched on and the model was again simulated with the series resonant filter but without the capacitor bank. The results are as shown in Figures 13 and 14 respectively. According to the result shown in Figure 13, the current waveform of series resonant filter model of NICHEMTEXT major industrial loads with series resonant harmonic filter but without capacitor bank was approximately undistorted in comparison to Figure $8 \mathrm{~b}$ and by using equation 15, the THD drastically reduced by $26.630 \%$, from $30.080 \%$ in Figure 10 to $3.460 \%$ in Figure 14 . The power factor equally improved from 0.860 to 0.894 .

\subsubsection{Simulation of Series Resonant Filter Model of NICHEMTEXT Major Industrial Loads with Series Resonance Harmonic Filter and Capacitor Bank}

Equally, the circuit breaker in Figure 6 was switched on and the model was once again simulated with both the series resonant filter and the capacitor bank incorporated in the system. The obtained results are presented in Figures 15 and 16.

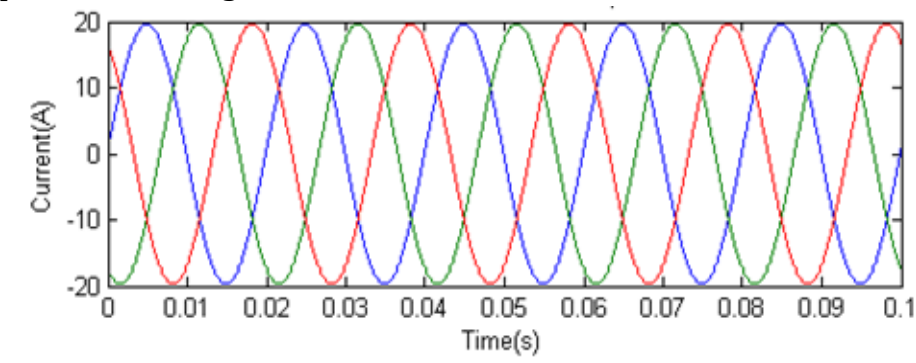

Figure 15: Current waveform of series resonant filter model of NICHEMTEXT major industrial loads with series resonant harmonic filter and with capacitor bank

Vol. 36, No. 2, April 2017 


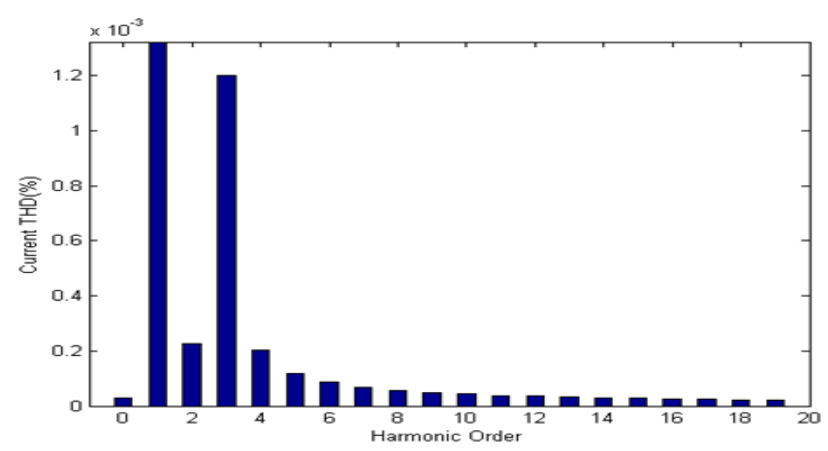

Figure 16: Current harmonic distortion of series resonant filter model of NICHEMTEXT major industrial loads with series resonant harmonic filter and capacitor bank at various harmonic orders

Figures 15 and 16 were the results of both series resonant filter and capacitor bank applied to the load. The series resonant filter mitigated the harmonics presented within the system and also compensated the power factor. The capacitor bank smoothened the waveform as seen from the undistorted sinusoidal waveform in Figure 15 compared to Figure 13 that was slightly distorted. The THD of current using equation 15 was reduced to $0.001 \%$ in Figure 16 compared to Figure 8b. Analysis also indicated that the power factor improved from 0.860 to 0.894 .

\subsection{Simulation of Parallel Resonant Filter Model of NICHEMTEXT Major Industrial Loads}

When parallel resonant filter was considered, the model of NICHEMTEXT major industrial loads presented in Figure 7 was simulated using MATLAB/Simulink software application earlier discussed. The total harmonic distortion of the system and the mitigation of the current harmonic contents with the use of capacitor banks and the designed parallel resonant filter were observed.

\subsubsection{Simulation of Parallel Resonant Filter Model of NICHEMTEXT Major Industrial Loads without Parallel Resonant Filter and Capacitor Bank}

The circuit breaker in Figure 7 was switched on and the model was simulated without parallel resonant filter and capacitor bank. The results obtained were the same as that of Figures 8, 9 and 10 respectively since it was simulation of the same system without a filter and a capacitor bank.

\subsubsection{Simulation of Parallel Resonant Filter Model of NICHEMTEXT Major Industrial Loads without Parallel Resonant Filter but with Capacitor Bank}

The model in Figure 7 was simulated with the capacitor bank and with the circuit breaker switched on, however, without the parallel resonant filter connected to the system. The results obtained were also the same as that of Figures 11 and 12 respectively since it was simulation of the same NICHEMTEXT Major Industrial Loads without a filter but with a capacitor bank.

\subsubsection{Simulation of Parallel Resonant Filter Model of NICHEMTEXT Major Industrial Loads with Parallel Resonant Filter but without Capacitor Bank}

The model in Figure 7 with the circuit breaker switched on was simulated with parallel resonant filter but without the capacitor bank. The obtained results are presented Figures 17 and 18 respectively. It was observed that total harmonic distortion reduced from $30.080 \%$ to $8.107 \%$ and the power factor reduced from 0.860 to 0.840 .

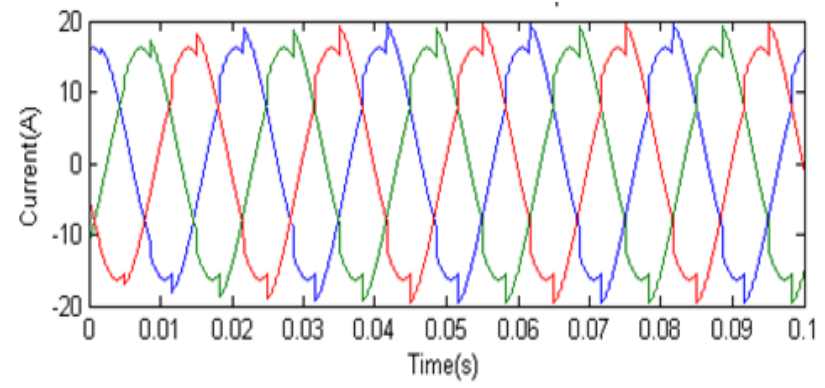

Figure 17: Current waveform of parallel resonant filter model of NICHEMTEXT major industrial loads with parallel resonant harmonic filter but without capacitor bank

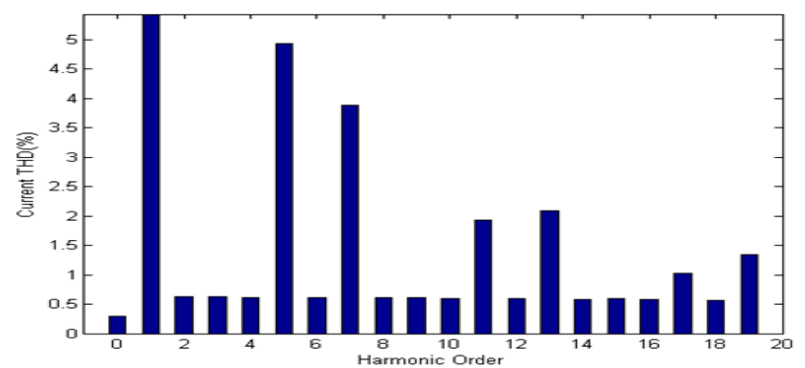

Figure 18: Current harmonic distortion of parallel resonant filter model of NICHEMTEXT major industrial loads with parallel resonant harmonic filter but without capacitor bank at various harmonic orders

\subsubsection{Simulation of Parallel Resonant Filter Model of NICHEMTEXT Major Industrial Loads with Parallel Resonant Filter and Capacitor Bank}

The circuit breaker in Figure 7 was switched on and the model was simulated with parallel resonant filter and capacitor bank in the system. Figures 19 and 20 respectively were the obtained results.

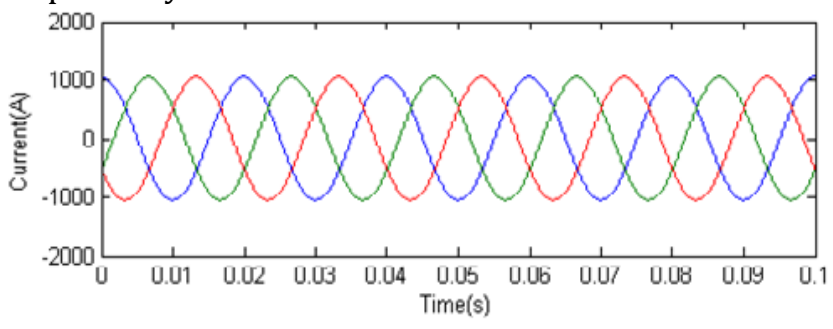

Figure 19: Current waveform of parallel resonant filter model of NICHEMTEXT major industrial loads with both parallel resonant harmonic filter and capacitor bank 


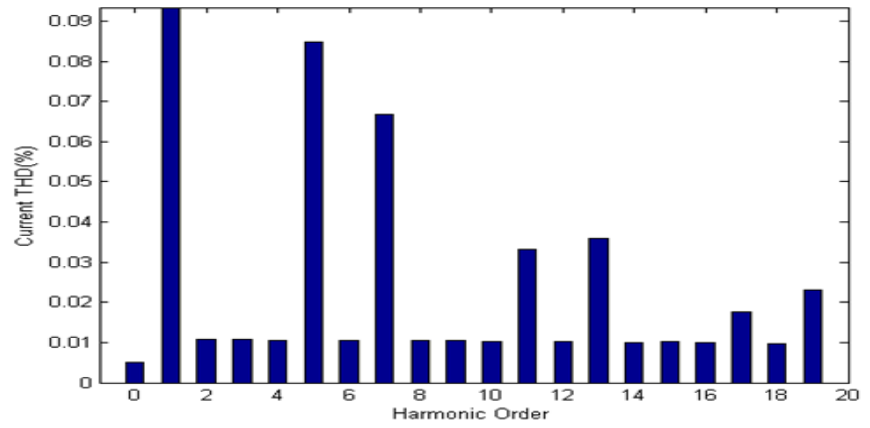

Figure 20: Current harmonic distortion of parallel resonant filter model of NICHEMTEXT major industrial loads with both parallel resonant harmonic filter and capacitor bank at various harmonic orders

From Figures 19, it is obvious that parallel resonant filter mitigated the harmonic distortion of Figure $8 \mathrm{~b}$ while the capacitor bank smoothened the waveform. The total harmonic distortion of current of Figure 20 reduced to $0.140 \%$ compared with that in Figure 10.However, the power factor reduced from 0.860 to 0.553 which is very low and unsafe for the supply system.

\subsection{Comparison of the Effects of Application of Series Resonant Filter and Parallel Resonant Filter to NICHEMTEXT Supply System}

The results of using the series resonant filter and parallel resonant filter for the supply system of NICHEMTEXT are compared as shown in Table 3.

From the Table 3, it is observed that the results of the simulations without the addition of the filters were the same for both cases. However, simulation with the parallel resonant filter but without capacitor bank showed that the harmonic distortion was mitigated to $8.107 \%$ whereas with the series resonant filter, it was mitigated to $3.460 \%$. Also, the use of series resonant filter without capacitor bank improved the power factor from 0.86 to 0.894 while the parallel resonant filter caused a reduction in the power factor from 0.860 to 0.840 .

Moreover, with capacitor bank included, the parallel resonant filter was able to mitigate the harmonic distortion to $0.140 \%$, while the series resonant filter showed better performance by mitigating the harmonic distortion to $0.001 \%$. The series resonant filter was also able to improve the power factor from 0.860 to 0.894 , while the parallel resonant filter caused a drastic decline in power factor from 0.860 to 0.553 , a result which is unacceptable.

\section{CONCLUSION}

Harmonics cause nuisance tripping of circuit breakers, over heating of motors, generators, transformers, over loading of neutrals and in some cases increases shutdown time in production, thereby affecting negatively the economics of the industry. This work considered series and parallel resonant harmonic filters to suppress harmonics using Simulink Simulate of the power system of NICHEMTEX, a Textile industry in Nigeria as a case study. From the analysis, series resonant filter mitigated the total harmonic distortion from $30.080 \%$ to $3.460 \%$. Moreso, with the installed capacitor bank in the industrial facility, the total harmonic distortion was reduced to $0.001 \%$ and power factor compensated from 0.860 to 0.894 .However, with the parallel resonant filter connected with the capacitor bank, harmonic distortion was mitigated to $0.140 \%$, and the power factor reduced to 0.553 , the value which is very low. Hence, it is observed that for this sample case, the use of series resonant filter mitigated the harmonics distortion and maintained power factors within the acceptable values.

\section{REFERENCES}

[1] Bollen, M. H. J. "Voltage Sags in Three Phase Systems", IEEE Power Engineering Reviews, Vol. 21, Number 9, pp. 8-11. 2013.

[2] Mohitkar, S. S. and Dhend, M. H. "Harmonic Measurement and Analysis of Variable Frequency Drive (vfd) in Industry", International Journal of Research in Advent Technology, Vol. 2, Number 2, pp. 303-309. 2014

[3] Mekhamer, S. F., Abdelaziz, A. Y. and Ismael, S. M. "Design Practices in Harmonic Analysis Studies Applied to Industrial Electrical Power Systems", Engineering, Technology and Applied Science Research, Vol. 3, Number 4, pp. 467-472. 2013.

[4] El-Sadek, M. Z. Power System Harmonics, Mukhtar Press, Egypt, 2007.

[5] Akagi, H. "Modern Active Filters and Traditional Passive Filters", Bulletin of the Polish Academy of Sciences: Technical Sciences, Vol. 54, Number 3, pp. 255-269. 2006.

Table 3: Comparison of the results obtained from parallel filter with that of series filter

\begin{tabular}{clcccc}
\hline \multirow{2}{*}{ S/N } & \multicolumn{2}{c}{ Simulations } & \multicolumn{2}{c}{ Parallel Filter } & \multicolumn{2}{c}{ Series Filter } \\
\cline { 3 - 5 } & & $I_{T H D} \%$ & Power factor & $I_{T H D} \%$ & Power factor \\
\hline 1 & Without resonant filter and capacitor bank & 30.080 & 0.858 & 30.080 & 0.858 \\
2 & Without resonant filter but with capacitor bank & 27.790 & 0.993 & 27.790 & 0.993 \\
3 & With resonant filter but without capacitor bank & 8.107 & 0.840 & 3.460 & 0.894 \\
4 & With resonant filter and capacitor bank & 0.140 & 0.553 & 0.001 & 0.894 \\
\hline
\end{tabular}


[6] Shahbaz, M. Active Harmonic Filtering of Distributed AC System. M.Sc. Dissertation, Department of Electric Power Engineering, Norwegian University of Science and Technology, Norway, 2012.

[7] Dutta, A. A., Sabley, M., Sudame, B. S. and Kadu, A. N. "Harmonic Compensation in Power System Using Active Power Filters", International Journal of Multidisciplinary and Current Research, Vol.1, Number 3, pp. 188-192. 2013.

[8] Lee, T-L, Wang, Y. C, Li, J-C and Guerrero, J. M. "Hybrid Active Filter with Variable Conductance for Harmonic Resonance Suppression in Industrial Power Systems", IEEE Transactions on Industrial Electronics, Vol. 62, Number 2, pp. 746-756. 2015.

[9] Schwanz, D., Bollen, M. and Larsson, A. "A Review of Solutions for Harmonic Mitigation", IEEE 17th International Conference on Harmonic and Quality of Power, October 16-19, pp. 131-136. 2016.

[10] de Campos, B. P., de Sousa, L. A. R. and Ribeiro, P. F. "Mitigation of Harmonic Distortion with Passive Filters", IEEE 17th International Conference on Harmonic and Quality of Power, October 16-19, pp. 504-509. 2016.

[11] Waggoner, J. H. "Analysis of Harmonics Current Minimization on Power System", IEEE conference on harmonics and quality of power, 2001, pp. 8693. 2001.
[12] Suriadi, S. M. Analysis of Harmonics Current Minimization on Power Distribution System Using Voltage Phase Shifting Concept. M.Sc. Dissertation, Universiti Sains Malaysia, 2006.

[13] Arrillaga, J., Bradley, D. A., and Bodger, P. S. Power System Harmonics, John Wiley \& Sons, New York, USA, 1985.

[14] Lowenstein, M. Z. The $3^{\text {rd }}$ Harmonic Blocking Filter: A Well Established Approach to Harmonic Current Mitigation. Retrieved October 20, 2015 from http://iaeimagazine.org/magazine/2003/01/16/th e-3rd-harmonic-blocking-filter-a-well-establishedapproach-to-harmonic-current-mitigation/, 2003.

[15] Gonzalez, D. A. and McCall, J. C. "Design of Filters to Reduce Harmonic Distortion in Industrial Power Systems", IEEE Trans. on Industrial Application, Vol. IA-23, pp. 504-511. 1987.

[16] Theraja, B. L. and Theraja, A. K. A Textbook of Electrical Technology, S. Chand Publisher, New Dehli, India, 2005.

[17] Dugan, R. C., McGranaghan, M. F., Santos, S., Beauty, H. W. Electrical Power System Quality, Mc-Graw Hill, New York, USA, 2003.

[18] IEEE Standard 519. IEEE recommended practices and requirements for harmonic control in electrical power systems, 1992. 